\title{
Lipids from Microalgae for Cosmetic Applications
}

\author{
Maria De Luca ${ }^{1,2,+}+^{\mathbb{D}}$, Ilaria Pappalardo ${ }^{1,3,+}$, Antonina Rita Limongi ${ }^{1,4} \mathbb{D}^{\mathbb{D}}$, Emanuele Viviano ${ }^{1,5} \mathbf{D}^{\mathbb{D}}$, \\ Rosa Paola Radice ${ }^{1,4}$ (D), Simona Todisco ${ }^{1}$, Giuseppe Martelli ${ }^{1}$, Vittoria Infantino ${ }^{1}$ (D) and Antonio Vassallo ${ }^{1,6}$, $*$ (D)
}

1 Department of Science, University of Basilicata, Viale dell'Ateneo Lucano 10, 85100 Potenza, Italy; maria.deluca@unibas.it (M.D.L.); ilaria.pappalardo@unibas.it (I.P.); antonina.limongi92@gmail.com (A.R.L.); emanueleviviano@gmail.com (E.V.); rosapaolaradice@gmail.com (R.P.R.); simona.todisco@unibas.it (S.T.); giuseppe.martelli@unibas.it (G.M.); vittoria.infantino@unibas.it (V.I.)

2 ALMACABIO Srl, C/so Italia 27, 39100 Bolzano, Italy

3 KAMABIO Srl, Via Al Boschetto 4/B, 39100 Bolzano, Italy

Bioinnova s.r.l.s., Via Ponte 9 Luci, 22, 85100 Potenza, Italy

5 Thema Informatik s.r.l., Via Ressel 2/F, 39100 Bolzano, Italy

6 Spinoff TNcKILLERS s.r.l., Viale dell'Ateneo Lucano 10, 85100 Potenza, Italy

* Correspondence: antonio.vassallo@unibas.it

+ These authors contributed equally to this work.

Citation: De Luca, M.; Pappalardo, I.; Limongi, A.R.; Viviano, E.; Radice, R.P.; Todisco, S.; Martelli, G.; Infantino, V;; Vassallo, A. Lipids from Microalgae for Cosmetic Applications. Cosmetics 2021, 8, 52. https://doi.org/ $10.3390 /$ cosmetics 8020052

Academic Editor: Enzo Berardesca

Received: 10 May 2021

Accepted: 15 June 2021

Published: 17 June 2021

Publisher's Note: MDPI stays neutral with regard to jurisdictional claims in published maps and institutional affiliations.

\begin{abstract}
In recent years, there has been considerable interest in using microalgal lipids in the food, chemical, pharmaceutical, and cosmetic industries. Several microalgal species can accumulate appreciable lipid quantities and therefore are characterized as oleaginous. In cosmetic formulations, lipids and their derivatives are one of the main ingredients. Different lipid classes are great moisturizing, emollient, and softening agents, work as surfactants and emulsifiers, give consistence to products, are color and fragrance carriers, act as preservatives to maintain products integrity, and can be part of the molecules delivery system. In the past, chemicals have been widely used but today's market and customers' demands are oriented towards natural products. Microalgae are an extraordinary source of lipids and other many bioactive molecules. Scientists' attention to microalgae cultivation for their industrial application is increasing. For the high costs associated, commercialization of microalgae and their products is still not very widespread. The possibility to use biomass for various industrial purposes could make microalgae more economically competitive.
\end{abstract}

Keywords: lipids; microalgae; cosmetic products; new ingredients

\section{Microalgae}

Microalgae are microscopic unicellular organisms with several sizes, structures, and forms [1-3]. The "microalgae" term ties together photosynthetic prokaryotic and eukaryotic microorganisms that grow rapidly and have the ability to live in different aquatic and terrestrial ecosystems. More than 50,000 species of them are known but a large number of microalgae remains still unexplored [4-6]. Microalgae differ from macroalgae commonly referred to as seaweed which are instead macroscopic and multicellular organisms [7].

The general term "algae" is not a taxonomic term, but is a common collective name for all the plant-like organisms which contain chlorophyll a, have oxygenic photosynthesis, and are not specialized land plants. There is no consensus among taxonomists around the world to use one classification system since these groups are revised continuously due to new genetic data. The current microalgal classification considers eight major phyla belonging to four kingdoms, Eubacteria, Protozoa, Chromista, and Plantae. The large majority of microalgae are nested in the Eukaryota domain and distributed in seven main phyla Euglenozoa, Cryptista, Haptophyta, Heterokontophyta, Glaucophyta, Rhodophyta, and Chlorophyta. Cyanobacteria are the only representative phylum of microalgae in the Prokaryota domain. Despite the low representation in this domain, Cyanobacteria are among the most copious phylum alongside Chlorophyta and Heterokontophyta phyla $[8,9]$. 
One of the main characteristics of microalgae is their color determined by the presence of pigments such as chlorophylls, carotenoids, and phycobiliproteins, responsible for green, yellow/orange, and red/blue colors, respectively [7].

Microalgae use solar energy, water, and inorganic nutrients to reduce $\mathrm{CO}_{2}$ into complex organic compounds. Some of them also have the ability to use some organic carbon, so their cultivation can be performed into three modes: Photoautotrophy, heterotrophy, and mixotrophy [4]. Microalgae also require nitrogen, phosphorus, sulfur as macronutrients, and potassium, iron, magnesium, calcium, and other micronutrients to support physiological activities [10].

Microalgae as photosynthetic organisms and compared to higher plants, have greater annual photon to natural biomass conversion efficiencies and no natural sensibility to seasonality [11]. Their high photosynthesis efficiency tied with their rapid growth and the ability to accumulate a large number of bioproducts within their cells make them a suitable candidate to serve as industrial raw material [12]. Microalgae present an original chemical composition and many substances of high biological value: They can accumulate a high percentage of lipids and they are an unconventional source of proteins and amino acids. They typically have a high carbohydrates content and other valuable compounds such as vitamins, antioxidants, and minerals [13]. The extraordinary diversity and complexity of microalgae are due to the fact that they are one of the oldest life forms on Earth and they have evolved and adapted over billions of years [7]. Microalgae cultivation for human purposes became increasingly important, precisely for their variety. The mass microalgae cultivation started in the early 1960s in Japan with the culture of Chlorella. Mexico was the first in the early 1970s to grow and harvest Spirulina. The third major marketing area for algae was Australia, with the growth of Dunaliella salina for the production of $\beta$ carotene. Plants were then subsequently built in the USA, Israel, and India [14]. Today, the largest commercial production of microalgae is mainly located in Asia. Spirulina, Chlorella, Haematococcus, Dunaliella are some examples of microalgae that currently are used for commercial purposes [6].

Microalgae are presented as new model organisms for a wide range of biotechnological applications including human and animal nutrition, cosmetics, pharmaceuticals, $\mathrm{CO}_{2}$ capture, bioenergy production, and nutrient removal from wastewater [15-17]. The most important biological activities of natural products from microalga are antioxidant, antiangiogenic, cytotoxic, anticancer, anti-obesity, and antimicrobial activities [16]. For these reasons, the mass culture and commercial production of microalgae have strengthened in the last few years but their industrial exploitation is at its early stages $[4,6]$.

\section{Lipids}

In the last few years, microalgae cultivation has focused on lipids production for commercial applications. Lipids are a diversified selection of compounds for which no internationally agreed definition occurs. Generally, they are chemically heterogeneous substances, insoluble in water, but soluble in non-polar solvents. Lipids all contain either fatty acyl/alkyl, sphingosine or isoprene fractions as their hydrophobic building blocks. According to their hydrophobic or amphipathic characteristics and chemically functional backbones, lipids have been classified into eight categories, fatty acyls, glycerolipids, glycerophospholipids, sphingolipids, sterol lipids, prenol lipids, saccharolipids, and polyketides, each of these eight lipid categories consists of further lipid classes and subclasses [18-20]. Lipids are involved in many vital cellular processes. Lipids are the main constituents of biological membranes thanks to their hydrophobic nature, and therefore constitute the physical basis of all living organisms. Another task that lipids accomplish is the storage of surplus energy for later consumption. Finally, lipids also play a role in extra and intracellular signaling processes, as they transduce signals and amplify regulatory cascades. In plants, lipids are also involved in the photosynthesis processes [21,22]. In addition to their role in the regulation of a variety of physiological processes, lipids are associated with abnormal metabolism in many diseases such as atherosclerosis, diabetes, 
obesity, Alzheimer's disease, and tumorigenesis [23]. The rapid progress in analytical chemistry techniques, mostly chromatographic separation methods and mass spectrometry identification techniques, alongside the wide knowledge in bioinformatics, led to the development of "lipidomics". Lipidomics is used to describe the complete lipid profiles and networks of cellular lipid metabolism within a cell, tissue or a biological system, and provides a powerful tool to quantify the changes in individual lipids that may help reveal lipid biomarkers in diseases, for example [24,25].

Alongside their biological importance, lipids are exploited for various commercial purposes. Lipids are a major component of food and their demand is increasing in food production and nutritional supplements for human food or animal feed, other important markets for oils are detergents, biofuels, lubricants, hydraulic fluids, inks, paints, and phytochemical compounds [26]. Growing consumer demand is increasingly oriented towards vegetal oils. An important aspect to consider is lipids susceptibility, strongly influenced by numerous factors. Most of all, lipids are prone to oxidation that negatively affects their biological activities. Oxidative stability depends on many intrinsic and extrinsic factors. First, variations in oxidative stability exist among different lipid classes. Oxidative susceptibility of lipids depends largely on the degree of unsaturation of fatty acids and the stereospecific positional distribution of fatty acids in the triacylglycerol (TAG) molecules. Environmental factors to which lipids are exposed during processing and storage may affect their oxidation rate. In addition, the presence of minor components in fats and oils also affects their oxidative stability in both positive and negative manners. Lipid oxidation has detrimental effects on food quality and human health, for example [27]. Therefore, it is necessary to minimize oxidation and improve the oxidative stability of lipid products. The addition of antioxidant or encapsulation strategies are techniques commonly employed for lipid molecules stabilization [28].

Plant-derived lipids are conventionally used to satisfy the high industrial request, particularly lipids derived from oilseeds such as palm, soy, rapeseed, and sunflower oils. The increasing lipid demand raised some questions, among them the reduced availability of cultivable lands and consumption of resources. Microorganisms represent a sustainable alternative to lipids sources. Both prokaryotic and eukaryotic microorganisms are known to produce lipids in different quantities and compositions [29]. When their lipid content exceeds $20 \%$ of dry biomass they are classified as "oleaginous". The three different family groups of oleaginous microorganisms are microalgae, fungi (molds and yeast), and bacteria [30-32].

\section{Lipids for Cosmetic Uses}

Cosmetics have always played an important role in society. They are stable and homogenized mixtures of substances, resulting from an exact combination of active principles, excipients, and additives that are respectively the ingredients responsible for the asserted cosmetic activity, the substances ensuring the desired pharmaceutical dosage form, and the substances added to preserve the product and to improve its organoleptic properties [33]. Cosmetics clean, perfume, protect or modify the appearance of the part of the human body where they are differently applied by rubbing, pouring, and spraying, such as epidermis, hair, nails, lips, external genital organs, teeth, mucous membranes of the oral cavity [34]. Therefore, the applications of cosmetics range from everyday hygiene products such as soap, shampoo, deodorant, and toothpaste to beauty items including perfumes and makeup. Cosmetics production is carefully regulated to ensure consumer safety [35]. Natural compounds have been used for these applications in the past but the cosmetic market progressively increased the use of many synthetic chemicals over time [36]. Mineral oils and waxes are examples of these. They are stable and dermatologically well-tolerated compounds, used to regulate the viscosity of formulations and for protective and lubricating properties. Mineral oils and waxes are prepared from naturally crude petroleum oil through various refining steps including distillation, extraction, crystallization, and purification to remove potentially toxic substances. Moreover, mineral 
oils are non-allergenic, are highly stable, and not susceptible to oxidation or rancidity [37]. Although stringent regulations apply, many concerns emerge for the possibility to find hazardous solvents traces in final formulations and consequent risks for human health. Hence, the intention to replace them with vegetable oils, still not fully implemented because chemicals are more competitive economically. Many concerns are emerging for all chemicals: In some cases, safety data are lacking for synthetic ingredients and they might cause hypersensitivity reactions, anaphylactic reactions, lethal poisonings or long time effects to users. Systematic monitoring of these substances can be made by testing their genetic toxicity, phototoxicity, photogenotoxicity, toxicokinetics, and carcinogenicity and new studies might reveal different toxicity data [38-41]. Furthermore, the daily use of many cosmetic products leads to continuous exposure to different chemicals. As a result, the synergistic interaction of different chemicals and additive action may occur due to the presence of the same ingredients in different products [42]. Due to these reasons, the need to substitute chemicals become increasingly imperative and lead cosmetic industries to incessantly look for innovations. One of the current challenges is finding natural ingredients to achieve customers' requests more and more often oriented by increased awareness about the importance to use quality products and environmentally sustainable [43]. Marine sources and specifically algae represent valid alternatives of new raw materials [34,44-46]. Currently, macroalgae-based cosmetic products are present on the market and they are progressively substituting synthetic equivalent products. These products can contain macroalgal extracts with different bioactive compounds or their purified form. Active substances that lead to macroalgae utilization in cosmetics are extremely different (polysaccharides, proteins, peptides, amino acids, fatty acids, sterols, glycolipids, phospholipids, pigments, phenolic compounds, vitamins) although they are mostly used as thickening and gelling agents. The world of microalgae is still to be explored even if some ingredients derived from them are already on the market [47,48].

Lipids constitute one among the different categories of cosmetic ingredients (Table 1). In addition to lipids of chemical origin, a wide range of vegetable and animal oils and fats can be used as neutral bases and bioactive ingredients but today the lipids and their derivatives in cosmetic formulations are of plant or biotechnological origin. The types of lipids commonly used in cosmetics include triacylglycerides, waxes, ceramides, glycerophospholipids, sterols, hydrogenated, esterified, and oxidized lipids [49-51].

Table 1. Properties and lipid molecules most common in cosmetic products.

\begin{tabular}{ll}
\hline \multicolumn{1}{c}{ Properties } & \multicolumn{1}{c}{ Lipids } \\
\hline Moisturizing and softening properties & $\begin{array}{l}\text { Hydrocarbons, fatty acids, fatty alcohols, } \\
\text { triacylglycerols, waxes, phospholipids, sterols }\end{array}$ \\
\hline Surfactant and emulsifier agents & Phospholipids, glycolipids, lipopeptides, fatty acids \\
\hline Texturizer agents & Waxes, alkenones, triacylglycerols \\
\hline Color carriers & Isoprenoids \\
\hline Fragrance carriers & Essential oils, triacylglycerols \\
\hline Preservative agents & Glycerolipids, sphingolipids \\
\hline Active ingredients & Glycerolipids, sphingolipids, sterols, isoprenoids, \\
\hline Molecule delivery & flavonoids \\
\hline
\end{tabular}

Lipids perform different functions in cosmetic formulations. They are moisturizing agents that limit water loss through different mechanisms. The first way is occlusion, obtained by placing a waterproof film on the skin to delay water evaporation from the surface. Substances typically used for these aims are hydrocarbons, fatty acids, fatty alcohols, vegetable waxes, phospholipids, and sterols. Another mechanism is realized by applying humectant substances to the skin surface to attract water. An additional form of 
moisturization is the use of hydrophilic matrices that forms a physical protective coating over the skin preventing evaporation. Then, photoprotection is considered an indirect form of moisturization using sunscreen ingredients that prevent cellular damage and related dehydration.

Lipids are emollient and softening agents that make the skin smooth and soft. Skin softness and smoothness are due to the capacity of thin oily substances to temporarily deposit between corneocytes making their edges smoother. Skin radiance and luminosity are closely related to the smoothness of the skin surface since they depend on the amount of light reflected by the skin surface improving skin appearance [52].

Lipids are used as surfactants and emulsifiers, to reduce surface tension between the skin's surface and product and to keep water and oil blended in a product. Surfactants reduce surface tension and facilitate the formation of emulsions between liquids of different polarities due to their chemical structure with hydrophobic and hydrophilic moieties. Their amphiphilicity performs detergency, wetting, emulsifying, solubilizing, dispersing, and foaming actions. In cosmetics, polyethylene glycol ethers are the most commonly used traditional commercial surfactants. Today, there is an increased use of biosurfactants, generally classified into glycolipids, lipopeptides, phospholipids, fatty acids, and polymeric compounds according to their chemical structures. The biosurfactants commonly used in cosmetics and personal care products are glycolipids due to their physico-chemical properties, biological activities, biocompatibility, and biodegradability and are used as multifunctional ingredients in the formulation of cosmetics. Sophorolipids, rhamnolipids, and mannosylerythritol lipids are the most known glycolipids with application to cosmetics and pharmaceutical technology $[53,54]$.

Lipids can also function as texturizers, to give consistency to gel-like products to improve spreadability and feel consistency, and as color and fragrance carriers [49]. Color and fragrance are two important characteristics for cosmetics selection among consumers. Pigments are examples of lipid colorful molecules for industrial applications [48]. Instead, essential oils can impart pleasant aromas in different products, besides, they can act as preservatives and active agents and, simultaneously, offer various benefits to the skin [55]. As preservative carriers, lipids can prevent bacteria growth [49]. The use of preservatives in cosmetic formulations is for bacterial contamination risk during use. There are several examples of the use of lipids as part of a preservative system in cosmetics. In the past, lipids have been used as penetration enhancers in cosmetics and recently they have been used as nanoparticles such as solid lipid nanospheres, liposomes, nanosomes, and nanostructured lipid carriers for bioactive molecule delivery [56].

\section{Microalgae as Lipids Bio-Factories}

Microalgae are a promising platform for a wide range of high-value compound production. The last decade has seen intensive interest in microalgal lipids that can be used in various fields, from food to chemical, pharmaceutical, and cosmetic. Microalgae can produce various types of lipids such as triacylglycerols, phospholipids, glycolipids or phytosterols, used for energy storage, as energy substrates, as structural components of the cell membrane, and for metabolic processes such as signal transduction, transcriptional and translational control, intercellular interactions, secretion, and transfer of vesicles. Typical lipid molecules found in microalgae are common in other high plants but there are some unusual lipids not present in other organisms [57].

Microalgae cultivation processes consist of many important steps to optimize the production of the desired amount of target products (Table 2). 
Table 2. Microalgae cultivation process and aims of each stage.

\begin{tabular}{|c|c|c|c|c|}
\hline Microalgae Selection & Cultivation & Harvesting & Extraction & Purification \\
\hline $\begin{array}{l}\text { Based on quality } \\
\text { and quantity of } \\
\text { lipids desired }\end{array}$ & $\begin{array}{l}\text { Balance between } \\
\text { biomass production } \\
\text { optimization and } \\
\text { production costs }\end{array}$ & $\begin{array}{l}\text { Separation of growth } \\
\text { medium and biomass }\end{array}$ & $\begin{array}{l}\text { Biomass pre-treatment } \\
\text { (for cell wall breaking) } \\
\text { and lipid recovery }\end{array}$ & Removal of impurities \\
\hline & $\begin{array}{ll}\text { - } & \text { Open systems } \\
\text { - } & \text { Closed systems }\end{array}$ & $\begin{array}{ll}\text { - } & \text { Centrifugation } \\
\text { - } & \text { Filtration } \\
\text { - } & \text { Sedimentation } \\
\text { - } & \text { Coagulation } \\
\text { - } & \text { Flocculation } \\
\text { - } & \text { Foam flotation } \\
& \text { methic-based } \\
& \text { meds }\end{array}$ & $\begin{array}{ll}\text { - } & \text { Mechanical } \\
\text { methods } \\
\text { - } & \text { Chemical } \\
\text { - } & \text { methods } \\
\text { Physical methods }\end{array}$ & $\begin{array}{ll}\text { - } & \text { Filtration } \\
\text { - } & \text { Chromatographic } \\
\text { methods }\end{array}$ \\
\hline
\end{tabular}

The first step is the selection of microalgae species. The specific composition and quantity of lipids are species-dependent and common oleaginous microalgae are Chlorella sp., Nannochloropsis sp., Scenedesmus sp., and Dunaliella sp. [58-60]. A suitable microalgae selection is crucial for production since cultivation conditions, harvesting, and extraction methods change accordingly to improve production efficiency, yield, and quality of the products [40]. Depending on the species selected and the objectives to be achieved, cultivation conditions may vary.

Currently, there are two primary types of mass-cultivation systems: Closed cultivation systems in photobioreactors and open cultivation systems in raceway ponds. The first allows controlling physical and chemical cultivation conditions such as temperature, $\mathrm{pH}$, aeration, mixing, light intensity, and growth mode. In addition, photobioreactors allow monitoring possible contaminations but the capital, operational, and energetic costs remain significantly high. The second are less complex and require a lower capital investment, indeed microalgae are exposed to full sunlight and cultivated at high concentrations to maximize biomass productivity $[11,61]$.

Microalgae accumulate lipids up to about $70-80 \%$ of their biomass weight under favorable conditions. In any case, the oil productivity of microalgae is higher if compared to the most commercially productive plant [59,62-65]. Even if the composition and quantity of lipids are species-dependent, the accumulation of lipids in microalgae can usually be induced by stress conditions. Under harsh environmental conditions, microalgae synthesize and produce various secondary metabolites to preserve their growth, among which lipids that act as an energy-rich carbon storage substrate that enables the cells to survive under transient extreme environmental conditions and additional amounts of carotenoids to alleviate the oxidative damage induced by stress conditions [66]. Although each species of microalgae has different optimal stress conditions for the overproduction of desired metabolites, the main external cultivation conditions affecting lipid productivity are light intensity, temperature, carbon dioxide, nutrient starvation, salinity stress, and metal stress. Stress conditions stimulate lipid production but might inhibit cell growth and induce oxidative damage. According to considerable analyses on technology and economy, a two-stage culture strategy can be an interesting way to enhance lipid productivity. In the first stage, the algae are cultivated under optimum conditions to promptly achieve an optimal cell density, in the second stage, cultivation conditions are changed to trigger the accumulation of lipids $[59,63,64,66]$. The stress caused by the depletion of the nutrients is a commonly used strategy to trigger the accumulation of energy storage metabolites such as lipids in microalgae [10]. In the literature, there are also several genetic approaches to increase lipid production of microalgae. Molecular approaches include random mutagenesis, genetic engineering including genome editing, and metabolic pathway engineering $[59,67,68]$. 
During microalgae cultivation, growth can be followed in several ways such as counting the total cells, through a particle analyzer, measuring the doubling time, and biomass productivity. When the desired quantity of final product is reached, it is necessary to remove water from the culture media for biomass recovery. This important harvesting process can be performed through different solid-liquid separation techniques such as centrifugation, filtration, sedimentation, coagulation, chemical flocculation, foam flotation, electrical-based methods or a combination of various methods. Harvesting is an important and costly step in the large-scale microalgae cultivation process, which means that their use on an industrial scale is not economically sustainable [40,69].

The following step is the extraction of lipid products. In the literature, several techniques were reported for microalgal lipids extraction, mostly used for lipids recovery for biodiesel production [70]. No method can be considered effective as each microalga species has very specific characteristics. Typical conventional extraction methods include mechanical, chemical, and physical processes. The cell wall breaking is the key factor for the success of the whole process of lipids extraction. The microalgal cell wall composition is variable depending on the species, generally, the cell wall consists of an extracellular polymeric structure composed of polysaccharides, proteoglycans, peptides, proteins, and associated inorganic elements [71]. Solvent extraction methods are common methods for lipids recovery. Extraction with solvents can be improved by several approaches of pretreatment of the biomass for weakening and breaking of the cell wall, whose effectiveness varies from one microalga to another. Multiple laboratory-scale microalgae cell disruption methods are available. An example of biomass pre-treatment method is grinding that involves mixing the freeze-dried biomass with liquid nitrogen through a ceramic mortar and pestle. Bead vortexing leads to microalgae cell walls breaking by grinding and agitating the cells on a solid surface of glass beads [70]. The expeller press through the application of a high mechanical pressure shatters and breaks the cells. Cells rupture can occur also with osmotic shock, realized whit hyper-osmotic or hypo-osmotic conditions or with thermolysis when the vessels containing algal cells are heated through a water bath [31]. Ultrasonic treatment and electroporation lead either to cells disruption, the first using the energy of high-frequency acoustic waves, the second with an external electric field [72]. The use of microwaves allows the extraction of lipids or other molecules [73]. When microalgal cells are exposed to the microwave, inter- and intramolecular movements are generated in cells with consequent heat generation. Intracellular heating causes water vapor, which disrupts the cells and subsequently opens the cell membrane [73]. In addition, the algicidal treatment exploits the capacity of some bacteria to attack and destroy target algae for the presence of hydrolytic enzymes able to break down the cell wall [70]. These techniques improve product recovery but are also potentially costly steps making biomass pretreatment an obstacle for large-scale production [16]. Various organic solvents or combinations of them have been suggested. Organic solvents are absorbed within the cell wall, and they cause swelling and rupture of the microalgal cell. In this way, the cell contents are available to be separated on the following step. Among organic solvents, a mixture of chloroform-methanol can efficiently extract lipids. The two traditional methods for lipids extraction, the Folch method [74] and Bligh and Dyer method [75], employed the mixture in different volume ratios: The sample is homogenized with the organic solvents and the addition of a saline solution leads to a phase separation and consequently lipids extraction [76-82]. Even though the extraction with chloroform is very effective, large-scale lipid extraction using these methods is excluded for environmental and health risks. Solvents such as ethanol, butanol, hexane, isopropanol, methyl-tert-butyl ether, acetic acid esters, and various combinations of different solvents have been examined, many of these are still harmful. More often, lipids extraction is carried out through a Soxhlet extractor. Soxhlet extraction is performed using solvents at boiling temperature and ambient pressure, and even if it requires a high amount of solvents and a long extraction time, it is capable of providing high yields and does not affect the bioactivity of the extracted molecules. An alternative is represented by green solvents residues, which have 
good solubilizing properties such as conventional solvents. They are environment-friendly solvents or bio-solvents, derived from natural or processing of agricultural. Examples are 2-methyltetrahydrofuran, ethyl acetate, ethyl lactate, and cyclopentyl methyl ether [83]. Other environment-friendly technologies over other conventional methods are supercritical fluid extraction [84], generally using carbon dioxide, and extraction with ionic liquids [12] that are considered as green, non-aqueous salt solutions, which contain both anions and cations. Liquid polymers and fluorous solvents are among the emerging green solvents. Liquid polymers are considered non-volatile class-based solvents, such as poly(ethylene glycol), poly(propylene glycol), poly(tetrahydrofuran), and poly(methylphenylsiloxane). The fluorous solvents are colorless, are free-flowing liquid, and have low toxicity. Various types are available, the mainly used are perfluorinated alkanes, perfluorinated dialkyl polyethers, and perfluorinated trialkylamines [70].

After extraction processes, further purification steps can be requested through filtration or chromatographic separation techniques [40].

The lipids of the microalgae can be considered an alternative raw material to classic natural sources for the market and today, different microalgal species are used as lipid bio-factories. Microalgae can produce various lipid categories (which will be illustrated below) with remarkable applications in various industries such as pharmaceuticals, foods and feed, cosmetics, and biofuel production. As previously mentioned, until a few years ago chemical synthesis represented the primary choice for the recovery of substances. Currently, there is a marked return to oils and fats of vegetable and animal origin to replace petroleum-based and synthetic products. The driving forces for this trend are primarily environmental and ecological. Oils and fats are renewable resources and do not cause an increase in $\mathrm{CO}_{2}$ production. In addition, their biodegradability is less complicated as compared to synthetic analogs.

Most of the industrial lipids, also in the cosmetic sector, come from plants such as sweet almond, avocado, Jojoba, copra, castor, and palm oils. The high use of environmental resources such as arable land and water represent the main problems in the use of vegetable lipids. Animal fats can be used as cosmetic additives. Lanolin, obtained from refined lamb's wool grease, and squalene, obtained from shark liver oil, have been used extensively. Today, animal fats are less used in cosmetic preparations for many reasons related to animals protection, environmental problems, and microbial contamination derived from animal infections [29].

Therefore, the use of microorganisms represents a valid alternative. Lipids producers microorganisms are bacteria, fungi, and microalgae, among them microalgae are a very interesting source. They have a strong environmental adaptation ability, do not need cultivable land for their growth, require less water than land crops, could accumulate high biomass quantity, and do not have a natural sensibility to seasonality. Microalgae include very different photosynthetic organisms and can accumulate a great variety of lipid molecules and other bioactive compounds in their cells. For these reasons, their use in the cosmetic sector is very interesting. However, production costs are the most significant obstacles that limit the production of microalgal oil in a large scale [85]. Different aquatic microalgae mainly from the genera Aphanizomenon, Arthrospira, Chlorella, Desmodesmus, Dunaliella, Haematococcus, Nannochloropsis, Scenedesmus, and Spirulina are broadly used in cosmetic and cosmeceutical applications [45].

Table 3 summarizes the main lipid categories with useful applications in cosmetics and the related microalgal species from which they are extracted. 
Table 3. Microalgal species and related lipid categories extracted.

\begin{tabular}{llll}
\hline \multicolumn{1}{c}{ Lipid Categories } & \multicolumn{1}{c}{ Microalgae Species } & References \\
\hline Triacylglycerols & $\begin{array}{l}\text { Chlorella sp., Nannochloropsis sp., Scenedesmus sp., } \\
\text { Dunaliella sp., Chlamydomonas sp. }\end{array}$ & [32] & $\begin{array}{l}\text { Nannochloropsis sp., Dunaliella sp., Schizochytrium sp., } \\
\text { Isochrysis sp., Tetraselmis sp. }\end{array}$ \\
\hline Polyunsaturated fatty acids & Diacronema lutheri, Tetraselmis sp., Nannochloropsis sp. & {$[88]$} & {$[89,90]$} \\
\hline Sterols & Euglena gracilis, Isochrysis sp. & {$[91-93]$} \\
\hline Waxes & $\begin{array}{l}\text { Dunaliella salina, Haematococcus pluvialis, Chlorella sp., } \\
\text { Scenedesmus sp., Muriellopsis sp., Spirulina sp., } \\
\text { Parotenoids }\end{array}$ & Porphyridium sp. & \\
\hline
\end{tabular}

\section{Microalgal Lipids for Cosmetic Applications}

Although most of the literature on microalgae lipids focuses on their use for biofuel production, many other sectors can exploit microalgal lipid properties, for example, food and feed fields. The most commonly used lipids for these sectors are omega- 3 and omega- 6 lipids, instead, as a renewable energy source a transesterification step is necessary for the production of fatty acid alkyl or methyl esters, commonly named biodiesel [31].

Moreover, cosmetic and pharmaceutical sectors show increasing interest in lipid with functional properties such as polyunsaturated fatty acids (PUFAs), phytosterols, and carotenoids $[16,94,95]$. In addition, oils are generally used as dermatological delivery agents, formulated into creams or emulsions to provide more uniform, efficacious application, and transport of active agents, as already mentioned.

In the next paragraphs, we shortly analyze the different lipid categories found in microalgae, classified according to the eight classes described in the classification system cited previously [20] and LIPID MAPS Structure Database [96]. Where possible, we describe their functions and properties for industrial application, particularly in the cosmetic field. The articles analyzed in this review were selected using the Pubmed and Google Scholar databases. After a first study of the literature concerning the general use of lipids in cosmetics, we focused our research on the lipids of microalgae. The selected works are those resulting from a research carried out by entering the individual lipid categories as keywords.

\subsection{Fatty Acyls}

Fatty acyls are one of the most important categories of biological lipids with a structure that represents the major lipid building block of complex lipids [20]. The category of fatty acyls sees further subdivision into subclasses, including fatty acids and conjugates, eicosanoids, fatty alcohols and esters, etc. In the cosmetic field, the fatty acyls group from oil seeds serve as the principal bio-based surfactant feedstock [97]. Biosurfactants are a diverse group of lipids with amphiphilic character containing both hydrophilic and hydrophobic domains within the molecule. This structural diversity of biosurfactants implies a large variety of biological and physicochemical properties. The main activity of these compounds is to lower interfacial tension allowing, for instance, solubilization of hydrophobic substances in water. Another frequent property of biosurfactants includes low critical micelle concentrations, allowing biosurfactants to exert their function at much lower concentrations than many chemically produced surfactants. Moreover, biosurfactants show prominent bioactivities including antibacterial, antifungal, and anti-tumor effects. Finally, they exhibit low eco-toxicity about excellent biological degradability preventing environmental accumulation [98]. Fatty acids (FA) consist of a hydrocarbon chain with a carboxyl group at one end. In cells, FAs can be free or bound. FA considered essential oily raw materials in cosmetic applications, can be used not only as emulsifiers but also as softeners, detergents, lighteners. They are thin oily substances capable of depositing 
between the desquamating corneocytes temporarily, making the skin smooth and soft and therefore brighter [52]. Many kinds of fatty acids can be used as raw materials, such as lauric acid, myristic acid, palmitic acid, and stearic acid. In addition, FAs are skin components as an important player in the maintenance of normal skin barrier function [99].

Microalgae contain a rich profile in PUFAs. They are fatty acids with more than one double bond in the carbon chain and they have many beneficial properties. Microalgae can synthesize members of the PUFAs $\omega-6$ family, including linoleic acid (LA), $\gamma$-linolenic acid (GLA), and arachidonic acid (ARA), as well as of the PUFAs $\omega-3$ family, including $\alpha$-linolenic acid (ALA), eicosapentaenoic acid (EPA), and docosahexaenoic acid (DHA) [62,100-103]. Many microalgae can synthesize the long chain of $\omega-3$ PUFAs, with yields greater than $20 \%$ of their total lipids. Marine members of the Thraustochytriacea and Crythecodiniacea families are the microalgae most currently used for the production of algal oil rich in $\omega-3$ and biomass [30]. They are important ingredients for food supplements and feeds for their evident beneficial effects on tissue integrity and health. Microalgae such as Chlorella vulgaris, Arthrospira platensis, Haematococcus pluvialis, Dunaliella salina have already been recognized as safe or authorized as additives for humans and animals. Other species that have been studied but that have not yet been marketed are Scenedesmus almeriensis and Nannocholoropsis sp. [87].

PUFAs have antioxidant and anti-inflammatory properties which prove to be very useful in different cosmetic formulations [104]. They help prevent heart disease [105] and inhibit the growth of cancerous cells [106]. PUFAs have shown positive effects in the treatment and prevention of various diseases including inflammatory ones, atherosclerosis, thrombosis, arthritis, and a variety of cancers. EPA and DHA (Figure 1) are the most valuable ones: They are associated with the reduction of complications in hypertension and show significant hypolipidemic activity, to reduce triglycerides and increase high-density lipoprotein cholesterol $[85,107,108]$. Furthermore, PUFAs contribute to the growth and performance of the retina [109], brain [110], and reproductive tissues [111]. In addition, PUFAs showed an antiproliferative effect on epithelial and bronchopulmonary cell cultures and improved glycogenesis in diabetic mice [111]. ARA and EPA promote the aggregative and vasoconstrictive action of platelets and the anti-aggregative and vasodilatory effects in the endothelium, as well as showing chemotactic action in neutrophils [100,112]. PUFAs derivates also play important roles. Particularly, the oxidative transformation of PUFAs results in a diverse family of lipid mediators named oxylipins, which play a key role in different metabolic responses, including their function in the resolution of inflammation [113-115]. For these reasons, all these lipids are also important for their biological activity when included in cosmetic formulations [116].

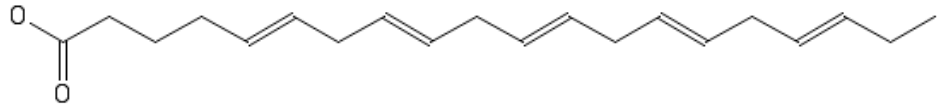

(a)

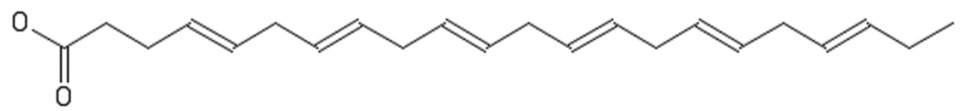

(b)

Figure 1. Chemical structures of some PUFAs produced by microalgae: (a) Chemical structure of EPA; (b) chemical structure of DHA.

Waxes fall into the fatty ester class, among the fatty acyl category [20]. Euglena gracilis is a microalga that accumulates a high amount of wax-ester as a by-product of the degradation process of storage polysaccharides, useful today for biofuel production but they could also prove helpful in cosmetics $[89,117,118]$. For example, waxes are key components in lipsticks since they provide appropriate rigidity, hardness, stability, and texture to the 
stick. A variety of waxes are available on the market today for lipsticks. Commonly used waxes are synthetic ingredients derived from petroleum but also mineral waxes derived from shale and animal or plant-derived ingredients are used. These last are often confined to certain parts of the world and their availability could be potentially affected by environmental factors. Alkenones are a family of unique lipids, long-chain ketones, biosynthesized by certain haptophyte microalgae including the Isochrysis sp. that are used as structuring agents in some cosmetic formulations in substitution to animal-derived and petroleum-derived waxes. They are a marine-based vegan and renewable ingredient that well answer consumer requests. Alkenones can be produced in many locations, therefore, their availability is not as limited as that of some other waxes. Given their waxy nature and reasonably high melting point, alkenones could represent an attractive class of natural ingredients that may find useful applications in a variety of cosmetic and personal care applications [90].

\subsection{Glycerophospholipids}

Glycerophospholipids, also known as phospholipids, are present in all organisms, including microalgae, and are key components of the lipid bilayer of cells. They provide a selectively permeable barrier that protects the cell from the outside and helps in the separation of the different intracellular organelles. In addition to their primary role in cellular membrane components, glycerophospholipids can influence cell signal transduction serving as binding sites for proteins and as second messengers or their derivatives [20]. There is also evidence that phospholipids are essential to many important biological processes, such as stress response and photosynthesis [119]. Their structure consists of a glycerol backbone with two hydrophobic acyl tails and a hydrophilic head group linked to the glycerol scaffold through phosphodiester linkage [24]. The major phospholipids are phosphatidylcholine (PC) (Figure 2), phosphatidylethanolamine (PE), phosphatidylglycerol (PG), and phosphatidylinositol (PI) [120]. The presence of both hydrophilic head groups and hydrophobic tails confers them amphiphilicity, which makes phospholipids excellent emulsifying agents and therefore can stabilize oil-water emulsions as delivery systems for food, cosmetic ingredients, and drugs [121]. Lecithins are a complex mixture of PC, PE, phosphatidylserine (PS), and PI, combined with various amounts of other substances such as triglycerides, fatty acids, and carbohydrates. They are used in foods as emulsifiers and surfactants to alter viscosity and crystallization properties. Lecithins are also used in the industrial field as an emulsifying agent in fabrics, leather, cosmetics, paints, plastics, and a release agent for concrete and insecticides [26].

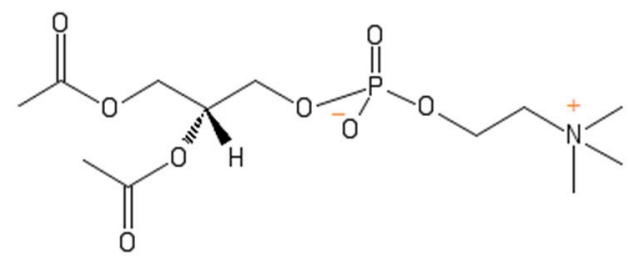

Figure 2. General structure of a PC.

\subsection{Glycerolipids}

Glycerolipids constitute the lipids category that encompasses all glycerol-containing lipids, except glycerophospholipids, which constitutes a separate category due to their abundance and important roles. The class of glycerolipids is dominated by the mono-, di-, and tri-substituted glycerols. Triacylglycerols (TAGs) are the most well-known glycerolipid category consisting of tri-substituted glycerols. They are responsible for energy storage in the cells [20,122] and their industrial application mainly concerns biofuel production $[63,123,124]$. Genera of microalgae used for biofuel production are Chlamydomonas, Chlorella, Nannochloropsis, Synechocystis, Tetraselmis, Monoraphidium, Ostreococcus, Tisochrysis, and Phaeodactylum [32]. TAGs from vegetable oils are also used in the formulation of 
bath products, cleansing products, eye makeup, fragrances, foot powders, facial makeup, personal cleanliness, suntan, and other skin products since they work as emollients. TAGs keep the skin's hydration level high since they form an occlusive layer on the skin that reduces the skin's water loss kinetics [42].

Chloroplast-specific glycolipids are monogalactosyldiacylglycerol (MGDG), digalactosyldiacylglycerol (DGDG) (Figure 3), and sulfoquinovosyldiacylglycerol (SQDG) that fall into the glycerolipids category. They are characterized by the presence of one or more sugar residues linked to glycerol via a glycosidic linkage, and they are primarily the constituents of thylakoid membranes in plant cells, including microalgae [120,122,125]. These lipids have been identified as possessing a variety of bioactivities, such as antioxidant and antimicrobial associated to the length of their fatty acyl chains, the number and position of the double bonds, the structure of the sugar moiety, and its anomeric configuration. It must be specified that several studies identified glycolipid fractions from algae having an antimicrobial activity even if only a few of these have been able to isolate and characterize the main molecular species responsible for this activity [126].

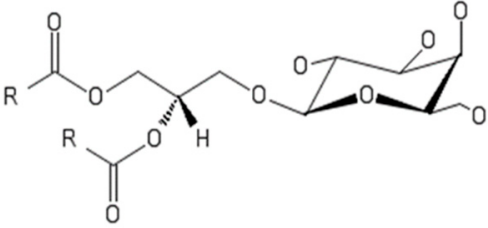

(a)

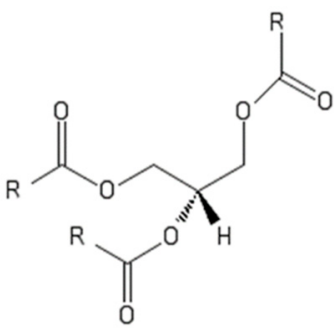

(b)

Figure 3. General structure of some glycolipids: (a) Chemical structure of a MGDG; (b) chemical structure of a DGDG.

\subsection{Sphingolipids}

Sphingolipids are a composite category of lipid molecules that share a common structural feature, a sphingoid base backbone consisting of an aliphatic amino alcohol group [20]. They play important structural and intracellular roles and take part in extracellular signaling. Moreover, they form specialized micro-domains in plasma membranes involved in different cellular processes, alongside sterols [57].

In the group of sphingolipids, different chemical structures were identified belonging to different sub-classes such as ceramides and glycosphingolipids, also known as cerebrosides. Ceramides are used in several skin care cosmetic products for regulating trans-epidermal water loss and promoting epidermal barrier repair. They are abundant lipids in the stratum corneum produced when barrier damage occurs and which become sphingolipids when glycosylated. Different ceramides have been identified and synthetically duplicated for inclusion in moisturizer formulations renowned by their polar head group structure, as well as by their hydrocarbon chain properties [49,52]. Moreover, these lipids have shown an antimicrobial activity [126]. Sphingolipids are widely distributed metabolites of microalgae but knowledge of these metabolites in microalgae remains poor [57].

\subsection{Sterol Lipids}

The sterols category includes molecules with different biological functions, and are characterized by the presence of a unique fused ring structure [20]. They constitute an important component of membrane lipids specifically for the optimal maintenance of membrane fluidity. Sterols present in microalgae are not only free but also in conjugated forms, many of them are unusual in terrestrial higher plants [57]. 
A great variety of sterols is present in plants and they are also called phytosterols. In the last few years, phytosterols have become particularly interesting for their beneficial health effects. Numerous studies have reported that phytosterols interact with cholesterol absorption through inhibitory mechanisms leading to reduction of low-density lipoprotein cholesterol in the blood. In addition, they protect against nervous system disorders and exhibit anti-oxidative, anti-inflammatory, anti-atherogenicity, and anti-cancer properties [57]. Current industrial sources for phytosterols are tall oil and vegetable oils but microalgae are an alternative source $[29,127]$. Phytosterols are found in all microalgal species. Recently, Diacronema lutheri, Tetraselmis sp. and Nannochloropsis sp. have been identified as the highest phytosterol producers, but other studies on the phytosterols content are done in different microalgae species and classes [88]. In some studies, phytosterols and the total lipid fraction isolated from microalgae are identified as responsible for an anti-inflammatory activity due to an increase of anti-inflammatory cytokines and decrease of pro-inflammatory cytokines secretion. Therefore, their use in animal feed could control immune responses during inflammation and minimize the use of antibiotics [128,129]. These biological activities make them useful in the cosmetic sector.

\subsection{Prenol Lipids}

Microalgae are also a source of natural pigments with lipid characteristics, particularly carotenoids. Carotenoids are isoprenoid molecules belonging to the prenol lipids category. The general structure of carotenoids consists of a tetraterpene backbone optionally flanked by terminating rings. These rings are either oxygenated or non-oxygenated and distinguish carotenoids between xanthophylls and carotenes, respectively [20,94]. It is possible to distinguish between primary and secondary carotenoids. The first are a structural and functional part of the photosynthetic system of microalgae, having both a light-harvesting role and also photo-protective role. The second are accumulated in the cytoplasm and have only a photo-protective function [130]. Carotenoids absorb light within a wavelength of $400-550 \mathrm{~nm}$ and are the source of the yellow, orange, and red color of microalgae [131]. Carotenoids have a wide range of practical applications. They have various medicinal properties that lead to their use in the pharmaceutical sector (anti-angiogenic, anti-cancer, anti-diabetic, anti-inflammatory, anti-obesity, anti-oxidant properties, cardio-protective, and photo-protective effects) [132]. In cosmetic formulations, carotenoids are used as active ingredients with biological activity for their antioxidant properties and nutritional value to the skin and hair. The chemical structure of carotenoids is responsible for their antioxidant activities. Carotenoids contain long conjugated double bonds in a polyene chain that are responsible for antioxidant activities by quenching singlet oxygen and scavenging radicals to terminate the chain reaction. They are known to play important roles in scavenging reactive oxygen species (ROS) but there is little information regarding their roles in cellular defenses against reactive nitrogen species (RNS) [132]. Fucoxanthin has a strong radicalscavenging activity due to the presence of the unusual double allenic bonds in its structure. Another important carotenoid with strong antioxidant activity is astaxanthin, which acts as a scavenger of various reactive species and exhibits higher levels of antioxidant activity than other carotenoids such as $\beta$-carotene, zeaxanthin, and canthaxanthin. Its powerful antioxidant activities result from the unique molecular structure. Astaxanthin contains a conjugated polyene chain at the center and hydroxy and keto moieties on each ionone ring. Astaxanthin shows better biological activity than other antioxidants since it can link with the cell membrane from the inside to the outside. The polyene chain in astaxanthin traps radicals in the cell membrane, while the terminal ring of astaxanthin can scavenge radicals both at the surface and in the interior of the cell membrane [133]. The anti-oxidant activity is of great importance in cosmetic formulations, especially for skincare products. Ultraviolet (UV)-exposure could determine the accumulation of high levels of ROS. Accumulation of ROS in cells causes cell death and excessive cell death can lead to wrinkling and dryness of the skin. ROS accumulation also plays an important role in photo-aging conditions such as cutaneous inflammation, melanoma, and skin cancer. The skin has naturally occurring 
antioxidant agents which can block the effects of ROS and suppress cell disruption and damage but these defenses may not provide adequate protection when levels of ROS are very high. Carotenoids can limit lipid peroxidation events by scavenging the ROS formed during photo-oxidative processes. Carotenoids protect humans from UV-light damage and are applied externally via the skin (as a topical treatment) as well as via dietary means. Moreover, they are also used in tan lotions due to their color [131].

Due to their color and nutritional properties, carotenoids are traditionally used in food and feed industries. They are vitamin precursors and their presence in a regular alimentation is fundamental since humans and animals are incapable of synthesizing them [130]. Carotenoids are considered safe natural dyes and are added to a variety of products to enhance their color. The animal feed sector was the highest consumer of carotenoids [132].

Nowadays, most of the carotenoids produced by the industry are chemically synthesized, although a small portion is obtained naturally from plants or algae. Their synthetic production is faster and cheaper since it requests low-cost labor and inexpensive chemicals, does not need living organisms, and there are no harvesting and extraction costs. Unfortunately, synthetic carotenoids are less effective in terms of their health-promoting properties to natural carotenoids and are hence less valuable and desirable as a product. Due to the adverse side effects commonly associated with drug therapy, public interest in recent times has focused on natural products with health-promoting properties as alternatives to conventional drugs. Consumers prefer naturally derived compounds in cosmetic formulations, so there is an increasing global demand for naturally derived carotenoids rather than those synthesized chemically [132].

The main carotenoids of microalgae are $\beta$-carotene, lycopene, astaxanthin (Figure 4), zeaxanthin, violaxanthin, and lutein [134], and the most common microalgae commercially interesting for pigment production are Dunaliella salina, Haematococcus pluvialis, Chlorella spp., Scenedesmus spp., Muriellopsis spp., Spirulina spp., Porphyridium spp. [91-93,95,130].

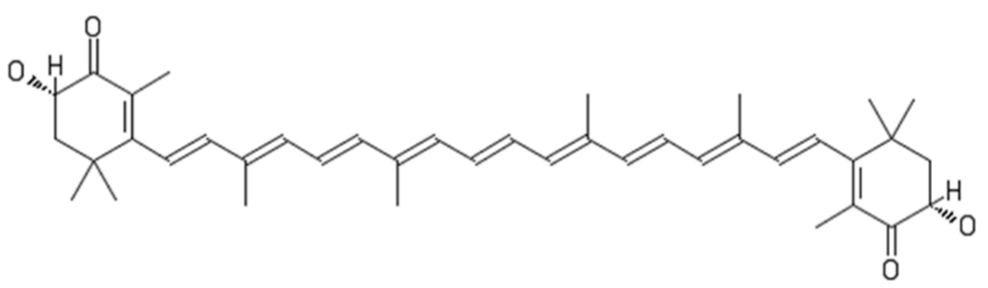

Figure 4. Chemical structure of astaxanthin.

\subsection{Polyketides}

Flavonoids are important secondary plant metabolites with a variable polyphenolic structure characterized by a heterocyclic oxygen linked to two aromatic rings, which vary in the level of hydrogenation and belonging to the polyketides lipid category [20]. They are widely present in fruits, vegetables, and foods and beverages of plant origin with functions related to various processes ranging from UV protection to signaling and pigmentation [135]. The beneficial health effects of these natural products are known for which they are now considered an indispensable component in a variety of nutraceutical, pharmaceutical, medicinal, and cosmetic applications for their antioxidant, anti-inflammatory, anti-mutagenic, and anti-carcinogenic properties together with their ability to modulate the key functions of cellular enzymes [135]. Although there are few studies, some scientists have found flavonoids also in microalgae [136-138]. 


\subsection{Saccharolipids}

Saccharolipids are another lipid class in the LIPID MAPS Structure Database. The term describes compounds in which fatty acyls are linked directly to a sugar backbone. This group is distinct from the term "glycolipid" that was defined by the International Union of Pure and Applied Chemists (IUPAC) as a lipid in which the fatty acyl portion of the molecule is present in a glycosidic linkage. It is necessary to specify that classification in LIPID MAPS Structure Database does not have a separated glycolipids category but instead places glycosylated lipids in appropriate categories based on their core lipids [20]. In literature, we found few studies that described their presence in microalgae $[139,140]$.

\section{Conclusions and Future Perspectives}

Microalgae are an interesting source of bioactive compounds with potential industrial applications. Lipids are a wide category of useful substances in many sectors. They are used in the enhancement of the nutritional value of food and animal feed, pharmaceutical industry, biodiesel production, etc. Microalgae lipids are most exploited as feedstock for third-generation biodiesel production. Different from the first and second generations of biodiesel that are mainly produced from edible and non-edible vegetable oils, respectively, biodiesel of the third generation is obtained from microbial oils, such as microalgal oil, representing a powerful alternative to traditional feedstock [141]. The industrial interest for algal lipid is also for the capacity of microalgae to synthesize considerable quantities of PUFAs $[100,142]$. PUFAs are essential nutrients for humans that lack the requisite enzymes to synthesize some of them. Fish and fish oil are the common sources of long-chain PUFAs but microalgae could be an interesting alternative $[143,144]$. Unfortunately, the global supply from all the traditional sources of these nutrients is insufficient to satisfy human nutritional requirements. In addition, fish oil is not recommended for vegetarians or people allergic to fish, has an unpleasant odor for some people, and may contain fatsoluble environmental pollutants. For these reasons, microalgae could be an interesting alternative [17,143-145].

Microalgae used in cosmetics is an interesting strategy to increment searching for new natural ingredients from environmentally sustainable biomass. Whole cells can be used to provide a mixture of molecules with useful properties. On the other hand, extracted molecules could also be proposed for targeting specific effects, since whole microalgae biomass is difficult to incorporate in cosmetic formulations [48]. Lipid products are a useful perspective for cosmetic formulations. To date, different lipids extraction methods are exploited but the recovery of algal oils has usually been carried out at a laboratory scale. Thus, it is necessary to test new extraction and purification methods possibly oriented versus green technologies. The selection of an appropriate extraction procedure is a crucial factor. In fact, a biocompatible buffer which does not alter the bioactivity of the extracted molecules needs to be used. Nowadays, conventional extraction techniques involve the use of organic solvents for a long time and also the use of dry biomass as a starting material. New techniques are being developed which do not require the involvement of toxic solvents, reduce the extraction time, improve the extraction yields without affecting the biological activity, and minimize environmental impact [146].

As already mentioned, lipids are used in different industrial sectors and are mostly of animal, plant or biotechnological origin. Recently, there was a return to natural compounds making the industrial market environmentally sustainable. Plants can be exploited for lipids recovery but involve the use of a large number of environmental resources such as arable land and water. In this context, microalgae could show numerous advantages. Microalgae have a strong environmental adaptation ability so they do not compete with terrestrial crops for arable land, they require less water, exhibit a rapid biomass production when in favorable conditions and show high oil contents, higher than land-based oleaginous crops. About the many advantages associated with microbial lipids production, the possibility to manipulate the genetic machinery of microorganisms to produce the desired lipid molecules with high economic value is most interesting. Alongside lipid production, 
microalgae could be exploited for the production of various bioactive molecules. The cosmetic sector is always in search of new ingredients for innovative product formulations. The present production of algae extracts in cosmetics is widely dominated by seaweeds and the use of microalgae was relatively secretive until the 2010s when the demand for beauty treatments started to grow significantly. The market for microalgae-based cosmetic products is expected to grow further. In fact, in the last years, there is great interest in cosmeceutic products defined as "cosmetic products with biologically active ingredients claiming medical or drug-like benefits" making thinner the edges between cosmetics and pharmaceutics. In addition to the properties of lipids already used in the cosmetic sector, such as moisturizing agents or surfactants, research has shown that there are numerous lipid categories with interesting biological activities, such as anti-inflammatory and antioxidant properties or anti-microbial activity becoming promising molecules to inactivate a wide spectrum of microorganisms [147]. Microalgae adapt well to the new requests of the market.

Despite intensive research efforts, the commercial use of microalgae biomass as a source of useful products is still not economically sustainable due to some problems. Significant obstacles that limit the production of microalgal lipids on a large scale are the restricted lipid synthesis in the microalgal cells and the low growth rate of these organisms, compared to other oleaginous microorganisms such as bacteria [148]. Another question is the monitoring of the different growth parameters of microalgae. Indeed, certain cultivation parameters, such as light intensity, temperature, starvation nutrients or other stress conditions, can affect the final biomass composition profile and specific lipids production. If closed cultivation systems allow monitoring cultivation conditions, the high costs associated make the open cultivation systems more competitive for industrial aims. Furthermore, the processing of microalgae biomass, such as extraction, isolation, and purification steps, is often complex and very expensive [149]. Although there are still numerous issues to be resolved in order to extend the production of lipids from microalgae on a large scale, microalgae are a promising sustainable resource for lipids and many other bioactive molecules production $[16,59,64,65]$. To make microalgae industrial utilization economically sustainable, alongside the genetic engineering of strains, lipids production from microalgae can be associated with other high-value metabolic products. It is possible to extract hydrophobic compounds and lipids at the same time and then purify them, while hydrophilic compounds such as proteins and sugars can be extracted from the defatted biomass. Furthermore, lipids can be co-products of environmental applications of microalgae, for example, for the treatment of wastewaters [85].

Author Contributions: Conceptualization, M.D.L., I.P. and A.V.; investigation, all authors; writingoriginal draft preparation, M.D.L. and I.P.; writing—review and editing, A.V., A.R.L., E.V., R.P.R., S.T., V.I. and G.M. All authors have read and agreed to the published version of the manuscript.

Funding: This research received no external funding.

Institutional Review Board Statement: Not applicable.

Informed Consent Statement: Not applicable.

Data Availability Statement: Not applicable.

Conflicts of Interest: The authors declare no conflict of interest.

\section{References}

1. Stark, M.; O'Gara, I. An Introduction to Photosynthetic Microalgae. Disruptive Sci. Technol. 2012, 1, 65-67. [CrossRef]

2. Singh, J.; Saxena, R.C. An Introduction to Microalgae: Diversity and Significance. In Handbook of Marine Microalgae: Biotechnology Advances; Academic Press: Cambridge, MA, USA, 2015; pp. 11-24, ISBN 9780128011249.

3. Venkatesan, J.; Manivasagan, P.; Kim, S.K. Marine Microalgae Biotechnology: Present Trends and Future Advances. In Handbook of Marine Microalgae: Biotechnology Advances; Elsevier Inc.: Amsterdam, The Netherlands, 2015; pp. 1-9, ISBN 9780128011249.

4. Gaignard, C.; Gargouch, N.; Dubessay, P.; Delattre, C.; Pierre, G.; Laroche, C.; Fendri, I.; Abdelkafi, S.; Michaud, P. New horizons in culture and valorization of red microalgae. Biotechnol. Adv. 2019, 37, 193-222. [CrossRef] [PubMed] 
5. Hamed, I. The Evolution and Versatility of Microalgal Biotechnology: A Review. Compr. Rev. Food Sci. Food Saf. 2016, 15, 1104-1123. [CrossRef]

6. Sathasivam, R.; Radhakrishnan, R.; Hashem, A.; Abd_Allah, E.F. Microalgae metabolites: A rich source for food and medicine. Saudi J. Biol. Sci. 2019, 26, 709-722. [CrossRef]

7. Levasseur, W.; Perré, P.; Pozzobon, V. A review of high value-added molecules production by microalgae in light of the classification. Biotechnol. Adv. 2020, 41, 107545. [CrossRef]

8. Borowitzka, M.A. The Physiology of Microalgae. In The Physiology of Microalgae; Springer: Cham, Switzerland, 2016; pp. 655-681, ISBN 9783319249452.

9. Heimann, K.; Huerlimann, R. Microalgal Classification: Major Classes and Genera of Commercial Microalgal Species. In Handbook of Marine Microalgae: Biotechnology Advances; Academic Press: Cambridge, MA, USA, 2015; pp. 25-41, ISBN 9780128011249.

10. Ran, W.; Wang, H.; Liu, Y.; Qi, M.; Xiang, Q.; Yao, C.; Zhang, Y.; Lan, X. Storage of starch and lipids in microalgae: Biosynthesis and manipulation by nutrients. Bioresour. Technol. 2019, 291, 121894. [CrossRef] [PubMed]

11. Perin, G.; Bellan, A.; Bernardi, A.; Bezzo, F.; Morosinotto, T. The potential of quantitative models to improve microalgae photosynthetic efficiency. Physiol. Plant. 2019, 166, 380-391. [CrossRef]

12. Tan, J.S.; Lee, S.Y.; Chew, K.W.; Lam, M.K.; Lim, J.W.; Ho, S.H.; Show, P.L. A review on microalgae cultivation and harvesting, and their biomass extraction processing using ionic liquids. Bioengineered 2020, 11, 116-129. [CrossRef]

13. Ravindran, B.; Gupta, S.K.; Cho, W.M.; Kim, J.K.; Lee, S.R.; Jeong, K.H.; Lee, D.J.; Choi, H.C. Microalgae potential and multiple roles-current progress and future prospects-an overview. Sustainability 2016, 8, 1215. [CrossRef]

14. Milledge, J.J. Commercial application of microalgae other than as biofuels: A brief review. Rev. Environ. Sci. Biotechnol. 2011, 10, 31-41. [CrossRef]

15. Chew, K.W.; Yap, J.Y.; Show, P.L.; Suan, N.H.; Juan, J.C.; Ling, T.C.; Lee, D.J.; Chang, J.S. Microalgae biorefinery: High value products perspectives. Bioresour. Technol. 2017, 229, 53-62. [CrossRef]

16. Khan, M.I.; Shin, J.H.; Kim, J.D. The promising future of microalgae: Current status, challenges, and optimization of a sustainable and renewable industry for biofuels, feed, and other products. Microb. Cell Fact. 2018, 17, 1-21. [CrossRef] [PubMed]

17. Spolaore, P.; Joannis-Cassan, C.; Duran, E.; Isambert, A. Commercial applications of microalgae. J. Biosci. Bioeng. 2006, 101, 87-96. [CrossRef]

18. Baumann, N.A.; Menon, A.K. Biochemistry of Lipids, Lipoproteins and Membranes, 4th ed.; Elsevier: Amsterdam, The Netherlands, 2002; Volume 36, ISBN 9780444511386.

19. Fahy, E.; Cotter, D.; Sud, M.; Subramaniam, S. Lipid classification, structures and tools. Biochim. Biophys. Acta 2011, 23, 1-7. [CrossRef] [PubMed]

20. Fahy, E.; Subramaniam, S.; Brown, H.A.; Glass, C.K.; Merrill, A.H.; Murphy, R.C.; Raetz, C.R.H.; Russell, D.W.; Seyama, Y.; Shaw, W.; et al. A comprehensive classification system for lipids. J. Lipid Res. 2005, 46, 839-861. [CrossRef] [PubMed]

21. Züllig, T.; Trötzmüller, M.; Köfeler, H.C. Lipidomics from sample preparation to data analysis: A primer. Anal. Bioanal. Chem. 2020, 412, 2191-2209. [CrossRef]

22. Li-beisson, Y.N.Y. Lipids in Plant and Algae Development; Springer: Berlin, Germany, 2016; Volume 86, ISBN 978-3-319-25977-2.

23. Wang, J.; Wang, C.; Han, X. Tutorial on lipidomics. Anal. Chim. Acta 2019, 1061, 28-41. [CrossRef] [PubMed]

24. Zhang, C.; Wang, K.; Yang, L.; Liu, R.; Chu, Y.; Qin, X.; Yang, P.; Yu, H. Lipid metabolism in inflammation-related diseases. Analyst 2018, 143, 4526-4536. [CrossRef]

25. O'Donnell, V.B.; Ekroos, K.; Liebisch, G.; Wakelam, M. Lipidomics: Current state of the art in a fast moving field. Wiley Interdiscip. Rev. Syst. Biol. Med. 2020, 12, 1-6. [CrossRef] [PubMed]

26. Tao, B.Y. Industrial Applications for Plant Oils and Lipids. In Bioprocessing for Value-Added Products from Renewable Resources; Elsevier: Amsterdam, The Netherlands, 2007; pp. 611-627, ISBN 9780444521149.

27. Fereidoon, S.; Ying, Z. Lipid oxidation and improving the oxidative stability. Chem. Soc. Rev. 2010, 39, 4067-4079. [CrossRef]

28. Lammari, N.; Louaer, O.; Meniai, A.H.; Fessi, H.; Elaissari, A. Plant oils: From chemical composition to encapsulated form use. Int. J. Pharm. 2021, 601, 120538. [CrossRef] [PubMed]

29. Stevens, C.; Verhé, R. Renewable Bioresources: Scope and Modification for Non-Food Applications; John Wiley and Sons: Hoboken, NJ, USA, 2004; ISBN 0470021047.

30. Da Silva, T.L.; Moniz, P.; Silva, C.; Reis, A. The dark side of microalgae biotechnology: A heterotrophic biorefinery platform directed to $\omega-3$ rich lipid production. Microorganisms 2019, 7, 670. [CrossRef]

31. Patel, A.; Karageorgou, D.; Rova, E.; Katapodis, P.; Rova, U.; Christakopoulos, P.; Matsakas, L. An overview of potential oleaginous microorganisms and their role in biodiesel and omega-3 fatty acid-based industries. Microorganisms $2020,8,434$. [CrossRef]

32. Tibocha-Bonilla, J.D.; Zuñiga, C.; Godoy-Silva, R.D.; Zengler, K. Advances in metabolic modeling of oleaginous microalgae. Biotechnol. Biofuels 2018, 11, 1-15. [CrossRef]

33. Couteau, C.; Coiffard, L. Phycocosmetics and Other Marine Cosmetics, Specific Cosmetics Formulated Using Marine Resources. Mar. Drugs 2020, 18, 322. [CrossRef] [PubMed]

34. Guillerme, J.B.; Couteau, C.; Coiffard, L. Applications for marine resources in cosmetics. Cosmetics 2017, 4, 35. [CrossRef] 
35. European Commission. Regulation (EC) No 1223/2009 of the European Parliament and of the Council. Off. J. Eur. Union L 2009, $342,59$.

36. Panico, A.; Serio, F.; Bagordo, F.; Grassi, T.; Idolo, A.; De Giorgi, M.; Guido, M.; Congedo, M.; De Donno, A. Skin safety and health prevention: An overview of chemicals in cosmetic products. J. Prev. Med. Hyg. 2019, 60, E50-E57. [CrossRef] [PubMed]

37. Chuberre, B.; Araviiskaia, E.; Bieber, T.; Barbaud, A. Mineral oils and waxes in cosmetics: An overview mainly based on the current European regulations and the safety profile of these compounds. J. Eur. Acad. Dermatol. Venereol. 2019, 33, 5-14. [CrossRef] [PubMed]

38. Petry, T.; Bury, D.; Fautz, R.; Hauser, M.; Huber, B.; Markowetz, A.; Mishra, S.; Rettinger, K.; Schuh, W.; Teichert, T. Review of data on the dermal penetration of mineral oils and waxes used in cosmetic applications. Toxicol. Lett. 2017, 280, 70-78. [CrossRef] [PubMed]

39. Morais, T.; Cotas, J.; Pacheco, D.; Pereira, L. Seaweeds compounds: An ecosustainable source of cosmetic ingredients? Cosmetics 2021, 8, 8. [CrossRef]

40. Yarkent, Ç.; Gürlek, C.; Oncel, S.S. Potential of microalgal compounds in trending natural cosmetics: A review. Sustain. Chem. Pharm. 2020, 17. [CrossRef]

41. Wang, J.; Liu, Y.; Kam, W.R.; Li, Y.; Sullivan, D.A. Toxicity of the cosmetic preservatives parabens, phenoxyethanol and chlorphenesin on human meibomian gland epithelial cells. Exp. Eye Res. 2020, 196, 108057. [CrossRef] [PubMed]

42. Birjandi Nejad, H.; Blasco, L.; Moran, B.; Cebrian, J.; Woodger, J.; Gonzalez, E.; Pritts, C.; Milligan, J. Bio-based Algae Oil: An oxidation and structural analysis. Int. J. Cosmet. Sci. 2020, 42, 237-247. [CrossRef] [PubMed]

43. Wang, H.M.D.; Chen, C.C.; Huynh, P.; Chang, J.S. Exploring the potential of using algae in cosmetics. Bioresour. Technol. 2015, 184, 355-362. [CrossRef] [PubMed]

44. Aslam, A.; Bahadar, A.; Liaquat, R.; Saleem, M.; Waqas, A.; Zwawi, M. Algae as an attractive source for cosmetics to counter environmental stress. Sci. Total Environ. 2021, 772, 144905. [CrossRef] [PubMed]

45. Stoyneva-Gärtner, M.; Uzunov, B.; Gärtner, G. Enigmatic microalgae from aeroterrestrial and extreme habitats in cosmetics: The potential of the untapped natural sources. Cosmetics 2020, 7, 27. [CrossRef]

46. Michalak, I.; Dmytryk, A.; Chojnacka, K. Algae Cosmetics. In Encyclopedia of Marine Biotechnology; John Wiley and Sons: Hoboken, NJ, USA, 2020.

47. Lourenço-Lopes, C.; Fraga-Corral, M.; Jimenez-Lopez, C.; Pereira, A.G.; Garcia-Oliveira, P.; Carpena, M.; Prieto, M.A.; SimalGandara, J. Metabolites from macroalgae and its applications in the cosmetic industry: A circular economy approach. Resources 2020, 9, 101. [CrossRef]

48. Morocho-Jácome, A.L.; Ruscinc, N.; Martinez, R.M.; de Carvalho, J.C.M.; Santos de Almeida, T.; Rosado, C.; Costa, J.G.; Velasco, M.V.R.; Baby, A.R. (Bio) Technological aspects of microalgae pigments for cosmetics. Appl. Microbiol. Biotechnol. 2020, 1-10. [CrossRef] [PubMed]

49. Hernandez, E.M. Pharmaceutical and Cosmetic Use of Lipids. In Bailey's Industrial Oil and Fat Products; Wiley: Hoboken, NJ, USA, 2020; pp. 1-28. [CrossRef]

50. Bonnet, C. Lipids, a natural raw material at the heart of cosmetics innovation. Oilseeds Fats Crop. Lipids 2018, 25, 4-5. [CrossRef]

51. Rabasco Álvarez, A.M.; Gonzalez Rodriguez, M.L. Lipids in pharmaceutical and cosmetic preparations. Grasas Aceites 2000, 51, 74-96. [CrossRef]

52. Draelos, Z.D. The science behind skin care: Moisturizers. J. Cosmet. Dermatol. 2018, 17, 138-144. [CrossRef]

53. Lourith, N.; Kanlayavattanakul, M. Natural surfactants used in cosmetics: Glycolipids. Int. J. Cosmet. Sci. 2009, 31, $255-261$. [CrossRef]

54. Varvaresou, A.; Iakovou, K. Biosurfactants in cosmetics and biopharmaceuticals. Lett. Appl. Microbiol. 2015, 61, 214-223. [CrossRef] [PubMed]

55. Sharmeen, J.B.; Mahomoodally, F.M.; Zengin, G.; Maggi, F. Essential Oils as Natural Sources of Fragrance Compounds for Cosmetics and Cosmeceuticals. Molecules 2021, 26, 666. [CrossRef]

56. Thormar, H. Lipids and Essential Oils as Antimicrobial Agents; John Wiley and Sons: Hoboken, NJ, USA, 2010; ISBN 9780470741788

57. Stonik, V.A.; Stonik, I.V. Sterol and sphingoid glycoconjugates from microalgae. Mar. Drugs 2018, 16, 514. [CrossRef]

58. Ma, R.; Wang, B.; Chua, E.T.; Zhao, X.; Lu, K.; Ho, S.H.; Shi, X.; Liu, L.; Xie, Y.; Lu, Y.; et al. Comprehensive utilization of marine microalgae for enhanced co-production of multiple compounds. Mar. Drugs 2020, 18, 467. [CrossRef] [PubMed]

59. Liang, M.-H.; Wang, L.; Wang, Q.; Zhu, J.; Jiang, J.-G. High-value bioproducts from microalgae: Strategies and progress. Crit. Rev. Food Sci. Nutr. 2019, 59, 2423-2441. [CrossRef] [PubMed]

60. Shin, Y.S.; Choi, H.I.; Choi, J.W.; Lee, J.S.; Sung, Y.J.; Sim, S.J. Multilateral approach on enhancing economic viability of lipid production from microalgae: A review. Bioresour. Technol. 2018, 258, 335-344. [CrossRef] [PubMed]

61. Barkia, I.; Saari, N.; Manning, S.R. Microalgae for high-value products towards human health and nutrition. Mar. Drugs 2019, 17, 304. [CrossRef]

62. Dolganyuk, V.; Andreeva, A.; Budenkova, E.; Sukhikh, S.; Babich, O.; Ivanova, S.; Prosekov, A.; Ulrikh, E. Study of morphological features and determination of the fatty acid composition of the microalgae lipid complex. Biomolecules 2020, 10, 1571. [CrossRef]

63. Ma, Y.; Gao, Z.; Wang, Q.; Liu, Y. Biodiesels from microbial oils: Opportunity and challenges. Bioresour. Technol. 2018, 263, 631-641. [CrossRef] [PubMed] 
64. Sun, X.M.; Ren, L.J.; Zhao, Q.Y.; Ji, X.J.; Huang, H. Microalgae for the production of lipid and carotenoids: A review with focus on stress regulation and adaptation. Biotechnol. Biofuels 2018, 11,1-16. [CrossRef]

65. Sun, X.M.; Ren, L.J.; Zhao, Q.Y.; Ji, X.J.; Huang, H. Enhancement of lipid accumulation in microalgae by metabolic engineering. Biochim. Biophys. Acta Mol. Cell Biol. Lipids 2019, 1864, 552-566. [CrossRef]

66. Shi, T.Q.; Wang, L.R.; Zhang, Z.X.; Sun, X.M.; Huang, H. Stresses as First-Line Tools for Enhancing Lipid and Carotenoid Production in Microalgae. Front. Bioeng. Biotechnol. 2020, 8, 1-9. [CrossRef]

67. Sun, X.M.; Ren, L.J.; Zhao, Q.Y.; Zhang, L.H.; Huang, H. Application of chemicals for enhancing lipid production in microalgae-a short review. Bioresour. Technol. 2019, 293, 122135. [CrossRef] [PubMed]

68. Park, S.; Nguyen, T.H.T.; Jin, E.S. Improving lipid production by strain development in microalgae: Strategies, challenges and perspectives. Bioresour. Technol. 2019, 292, 121953. [CrossRef]

69. Singh, G.; Patidar, S.K. Microalgae harvesting techniques: A review. J. Environ. Manag. 2018, 217, 499-508. [CrossRef] [PubMed]

70. Kumar, V.; Arora, N.; Nanda, M.; Pruthi, V. Different cell disruption and lipid extraction methods from microalgae for biodiesel production. In Microalgae Biotechnology for Development of Biofuel and Wastewater Treatment; Springer: Singapore, 2019; pp. 265-292, ISBN 9789811322648.

71. Borowitzka, M.A.; Moheimani, N.R. Solvent Extraction for Microalgae Lipids. In Algae for Biofuels and Energy; Springer: Dordrecht, The Netherlands, 2013; pp. 187-205, ISBN 9789400754799.

72. Patel, A.; Mikes, F.; Matsakas, L. An overview of current pretreatment methods used to improve lipid extraction from oleaginous microorganisms. Molecules 2018, 23, 1562. [CrossRef]

73. Kapoore, R.; Butler, T.; Pandhal, J.; Vaidyanathan, S. Microwave-Assisted Extraction for Microalgae: From Biofuels to Biorefinery. Biology 2018, 7, 18. [CrossRef]

74. Folch, J.; Lees, M.; Sloane Stanley, G. A simple method for the isolation and purification of total lipides from animal tissues. J. Biol. Chem. 1957, 226, 497-509. [CrossRef]

75. Bligh, E.G.; Dyer, W.J. A rapid method of total lipid extraction and purification. Can. J. Biochem. Physiol. 1959, 37, 911-917. [CrossRef]

76. Ben-Amotz, A.; Tornabene, T.G.; Thomas, W.H. Chemical Profile of Selected Species of Microalgae with Emphasis on Lipids. J. Phycol. 1985, 21, 72-81. [CrossRef]

77. Berge, J.P.; Gouygou, J.P.; Dubacq, J.P.; Durand, P. Reassessment of lipid composition of the diatom, Skeletonema costatum. Phytochemistry 1995, 39, 1017-1021. [CrossRef]

78. Grima, E.M.; Medina, A.R.; Giménez, A.G.; Sánchez Pérez, J.A.; Camacho, F.G.; García Sánchez, J.L. Comparison between extraction of lipids and fatty acids from microalgal biomass. J. Am. Oil Chem. Soc. 1994, 71, 955-959. [CrossRef]

79. Halim, R.; Danquah, M.K.; Webley, P.A. Extraction of oil from microalgae for biodiesel production: A review. Biotechnol. Adv. 2012, 30, 709-732. [CrossRef]

80. Kumari, N.; Singh, R.K. Biofuel and co-products from algae solvent extraction. J. Environ. Manag. 2019, 247, 196-204. [CrossRef]

81. Robles Medina, A.; Molina Grima, E.; Giménez Giménez, A.; Ibáñez González, M.J. Downstream processing of algal polyunsaturated fatty acids. Biotechnol. Adv. 1998, 16, 517-580. [CrossRef]

82. Xu, L.; Wim Brilman, D.W.F.; Withag, J.A.M.; Brem, G.; Kersten, S. Assessment of a dry and a wet route for the production of biofuels from microalgae: Energy balance analysis. Bioresour. Technol. 2011, 102, 5113-5122. [CrossRef]

83. Santoro, I.; Nardi, M.; Benincasa, C.; Costanzo, P.; Giordano, G.; Procopio, A.; Sindona, G. Sustainable and selective extraction of lipids and bioactive compounds from microalgae. Molecules 2019, 24, 4347. [CrossRef] [PubMed]

84. Molino, A.; Larocca, V.; Di Sanzo, G.; Martino, M.; Casella, P.; Marino, T.; Karatza, D.; Musmarra, D. Extraction of bioactive compounds using supercritical carbon dioxide. Molecules 2019, 24, 782. [CrossRef] [PubMed]

85. Bellou, S.; Baeshen, M.N.; Elazzazy, A.M.; Aggeli, D.; Sayegh, F.; Aggelis, G. Microalgal lipids biochemistry and biotechnological perspectives. Biotechnol. Adv. 2014, 32, 1476-1493. [CrossRef]

86. Tocher, D.R.; Betancor, M.B.; Sprague, M.; Olsen, R.E.; Napier, J.A. Omega-3 long-chain polyunsaturated fatty acids, EPA and DHA: Bridging the gap between supply and demand. Nutrients 2019, 11, 89. [CrossRef] [PubMed]

87. Molino, A.; Iovine, A.; Casella, P.; Mehariya, S.; Chianese, S.; Cerbone, A.; Rimauro, J.; Musmarra, D. Microalgae characterization for consolidated and new application in human food, animal feed and nutraceuticals. Int. J. Environ. Res. Public Health 2018, 15, 2436. [CrossRef]

88. Le Goff, M.; Le Ferrec, E.; Mayer, C.; Mimouni, V.; Lagadic-Gossmann, D.; Schoefs, B.; Ulmann, L. Microalgal carotenoids and phytosterols regulate biochemical mechanisms involved in human health and disease prevention. Biochimie 2019, 167, 106-118. [CrossRef]

89. Ogawa, T.; Tamoi, M.; Kimura, A.; Mine, A.; Sakuyama, H.; Yoshida, E.; Maruta, T.; Suzuki, K.; Ishikawa, T.; Shigeoka, S. Enhancement of photosynthetic capacity in Euglena gracilis by expression of cyanobacterial fructose-1,6-/sedoheptulose-1,7bisphosphatase leads to increases in biomass and wax ester production. Biotechnol. Biofuels 2015, 8, 1-11. [CrossRef] [PubMed]

90. Huynh, A.; Maktabi, B.; Reddy, C.M.; O’Neil, G.W.; Chandler, M.; Baki, G. Evaluation of alkenones, a renewably sourced, plant-derived wax as a structuring agent for lipsticks. Int. J. Cosmet. Sci. 2020, 42, 146-155. [CrossRef]

91. Xu, Y.; Ibrahim, I.M.; Wosu, C.I.; Ben-Amotz, A.; Harvey, P.J. Potential of new isolates of dunaliella salina for natural $\beta$-carotene production. Biology 2018, 7, 14. [CrossRef] 
92. Shah, M.M.R.; Liang, Y.; Cheng, J.J.; Daroch, M. Astaxanthin-Producing Green Microalga Haematococcus pluvialis: From Single Cell to High Value Commercial Products. Front. Plant. Sci. 2016, 7, 531. [CrossRef]

93. Ambati, R.R.; Gogisetty, D.; Aswathanarayana, R.G.; Ravi, S.; Bikkina, P.N.; Bo, L.; Yuepeng, S. Industrial potential of carotenoid pigments from microalgae: Current trends and future prospects. Crit. Rev. Food Sci. Nutr. 2019, 59, 1880-1902. [CrossRef]

94. Zerres, S.; Stahl, W. Carotenoids in human skin. Biochim. Biophys. Acta Mol. Cell Biol. Lipids 2020, 1865, 158588. [CrossRef]

95. Cezare-Gomes, E.A.; del Carmen Mejia-da-Silva, L.; Pérez-Mora, L.S.; Matsudo, M.C.; Ferreira-Camargo, L.S.; Singh, A.K.; de Carvalho, J.C.M. Potential of Microalgae Carotenoids for Industrial Application. Appl. Biochem. Biotechnol. 2019, 188, 602-634. [CrossRef]

96. LIPID MAPS. Available online: https:/ / www.lipidmaps.org/ (accessed on 9 May 2021).

97. Hayes, D.G.; Smith, G.A. Biobased Surfactants: Overview and Industrial State of the Art. In Biobased Surfactants; Elsevier Inc.: Amsterdam, The Netherlands, 2019; pp. 3-38, ISBN 9780128127056.

98. Kubicki, S.; Bollinger, A.; Katzke, N.; Jaeger, K.E.; Loeschcke, A.; Thies, S. Marine biosurfactants: Biosynthesis, structural diversity and biotechnological applications. Mar. Drugs 2019, 17, 408. [CrossRef]

99. Yang, M.; Zhou, M.; Song, L. A review of fatty acids influencing skin condition. J. Cosmet. Dermatol. 2020, 19, 3199-3204. [CrossRef] [PubMed]

100. Camacho, F.; Macedo, A.; Malcata, F. Potential industrial applications and commercialization of microalgae in the functional food and feed industries: A short review. Mar. Drugs 2019, 17, 312. [CrossRef] [PubMed]

101. Jónasdóttir, S.H. Fatty acid profiles and production in marine phytoplankton. Mar. Drugs 2019, 17, 151. [CrossRef] [PubMed]

102. Yang, Y.H.; Du, L.; Hosokawa, M.; Miyashita, K.; Kokubun, Y.; Arai, H.; Taroda, H. Fatty acid and lipid class composition of the microalga Phaeodactylum tricornutum. J. Oleo Sci. 2017, 66, 363-368. [CrossRef] [PubMed]

103. Maltsev, Y.; Maltseva, K. Fatty Acids of Microalgae: Diversity and Applications; Springer: Dordrecht, The Netherlands, 2021; Volume 3, ISBN 0123456789.

104. Plaza, M.; Herrero, M.; Cifuentes, A.; Ibáñez, E. Innovative natural functional ingredients from microalgae. J. Agric. Food Chem. 2009, 57, 7159-7170. [CrossRef] [PubMed]

105. Mozaffarian, D.; Wu, J.H.Y. Omega-3 fatty acids and cardiovascular disease: Effects on risk factors, molecular pathways, and clinical events. J. Am. Coll. Cardiol. 2011, 58, 2047-2067. [CrossRef] [PubMed]

106. Xu, Y.; Qian, S.Y. Anti-cancer activities of $\omega-6$ polyunsaturated fatty acids. Biomed. J. 2014, 37, 112-119. [CrossRef] [PubMed]

107. Colussi, G.; Catena, C.; Novello, M.; Bertin, N.; Sechi, L.A. Impact of omega-3 polyunsaturated fatty acids on vascular function and blood pressure: Relevance for cardiovascular outcomes. Nutr. Metab. Cardiovasc. Dis. 2017, 27, 191-200. [CrossRef]

108. Watanabe, Y.; Tatsuno, I. Prevention of Cardiovascular Events with Omega-3 Polyunsaturated Fatty Acids and the Mechanism Involved. J. Atheroscler. Thromb. 2020, 27, 183-198. [CrossRef]

109. Albouery, M.; Buteau, B.; Grégoire, S.; Martine, L.; Gambert, S.; Bron, A.M.; Acar, N.; Chassaing, B.; Bringer, M.A. Impact of a high-fat diet on the fatty acid composition of the retina. Exp. Eye Res. 2020, 196, 108059. [CrossRef] [PubMed]

110. Sun, G.Y.; Simonyi, A.; Fritsche, K.L.; Chuang, D.Y.; Hannink, M.; Gu, Z.; Greenlief, C.M.; Yao, J.K.; Lee, J.C.; Beversdorf, D.Q. Docosahexaenoic acid (DHA): An essential nutrient and a nutraceutical for brain health and diseases. Prostaglandins Leukot. Essent. Fat. Acids 2018, 136, 3-13. [CrossRef] [PubMed]

111. Moreau, D.; Tomasoni, C.; Jacquot, C.; Kaas, R.; Le Guedes, R.; Cadoret, J.P.; Muller-Feuga, A.; Kontiza, I.; Vagias, C.; Roussis, V.; et al. Cultivated microalgae and the carotenoid fucoxanthin from Odontella aurita as potent anti-proliferative agents in bronchopulmonary and epithelial cell lines. Environ. Toxicol. Pharmacol. 2006, 22, 97-103. [CrossRef] [PubMed]

112. Bazinet, R.P.; Layé, S. Polyunsaturated fatty acids and their metabolites in brain function and disease. Nat. Rev. Neurosci. 2014, 15, 771-785. [CrossRef]

113. Ávila-Román, J.; Talero, E.; Rodríguez-Luna, A.; García-Mauriño, S.; Motilva, V. Anti-inflammatory effects of an oxylipincontaining lyophilised biomass from a microalga in a murine recurrent colitis model. Br. J. Nutr. 2017, 116, 2044-2052. [CrossRef]

114. Ávila-Román, J.; Talero, E.; de los Reyes, C.; García-Mauriño, S.; Motilva, V. Microalgae-derived oxylipins decrease inflammatory mediators by regulating the subcellular location of NFKB and PPAR- $\gamma$. Pharmacol. Res. 2018, 128, 220-230. [CrossRef]

115. De Los Reyes, C.; Ávila-Román, J.; Ortega, M.J.; De La Jara, A.; García-Mauriño, S.; Motilva, V.; Zubía, E. Oxylipins from the microalgae Chlamydomonas debaryana and Nannochloropsis gaditana and their activity as TNF- $\alpha$ inhibitors. Phytochemistry 2014, 102, 152-161. [CrossRef]

116. Huang, T.H.; Wang, P.W.; Yang, S.C.; Chou, W.L.; Fang, J.Y. Cosmetic and therapeutic applications of fish oil's fatty acids on the skin. Mar. Drugs 2018, 16, 256. [CrossRef]

117. Yamada, K.; Nitta, T.; Atsuji, K.; Shiroyama, M.; Inoue, K.; Higuchi, C.; Nitta, N.; Oshiro, S.; Mochida, K.; Iwata, O.; et al. Characterization of sulfur-compound metabolism underlying wax-ester fermentation in Euglena gracilis. Sci. Rep. 2019, 9, 1-7. [CrossRef] [PubMed]

118. Yamada, K.; Suzuki, H.; Takeuchi, T.; Kazama, Y.; Mitra, S.; Abe, T.; Goda, K.; Suzuki, K.; Iwata, O. Efficient selective breeding of live oil-rich Euglena gracilis with fluorescence-activated cell sorting. Sci. Rep. 2016, 6, 2-9. [CrossRef] [PubMed]

119. Lu, S.; Wang, J.; Ma, Q.; Yang, J.; Li, X.; Yuan, Y.J. Phospholipid Metabolism in an Industry Microalga Chlorella sorokiniana: The Impact of Inoculum Sizes. PLoS ONE 2013, 8, e70827. [CrossRef]

120. Khozin-goldberg, I. Lipid Metabolism in Microalgae. In The Physiology of Microalgae; Springer: Cham, Switzerland, 2016; ISBN 9783319249452. 
121. Li, J.; He, Y.; Anankanbil, S.; Guo, Z. Phospholipid-Based Surfactants. In Biobased Surfactants; Elsevier Inc.: Amsterdam, The Netherlands, 2019; pp. 243-286, ISBN 9780128127056.

122. Degraeve-Guilbault, C.; Bréhélin, C.; Haslam, R.; Sayanova, O.; Marie-Luce, G.; Jouhet, J.; Corellou, F. Glycerolipid characterization and nutrient deprivation-associated changes in the green picoalga Ostreococcus tauri. Plant. Physiol. 2017, 173, 2060-2080. [CrossRef]

123. Karpagam, R.; Jawaharraj, K.; Gnanam, R. Review on integrated biofuel production from microalgal biomass through the outset of transesterification route: A cascade approach for sustainable bioenergy. Sci. Total Environ. 2021, 766, 144236. [CrossRef]

124. Yin, Z.; Zhu, L.; Li, S.; Hu, T.; Chu, R.; Mo, F.; Hu, D.; Liu, C.; Li, B. A comprehensive review on cultivation and harvesting of microalgae for biodiesel production: Environmental pollution control and future directions. Bioresour. Technol. 2020, 301, 122804. [CrossRef]

125. Sato, N.; Tsuzuki, M. Isolation and identification of chloroplast lipids. Methods Mol. Biol. 2011, 684, 95-104. [PubMed]

126. Alves, E.; Dias, M.; Lopes, D.; Almeida, A.; Domingues, M.D.R.; Rey, F. Antimicrobial lipids from plants and marine organisms: An overview of the current state-of-the- art and future prospects. Antibiotics 2020, 9, 441. [CrossRef] [PubMed]

127. Volkman, J.K. Sterols in Microalgae. In The Physiology of Microalgae; Springer International Publishing: Cham, Switzerland, 2016; pp. 485-505, ISBN 9783319249452.

128. Ciliberti, M.G.; Albenzio, M.; Francavilla, M.; Neglia, G.; Esposito, L.; Caroprese, M. Extracts from microalga chlorella sorokiniana exert an anti-proliferative effect and modulate cytokines in sheep peripheral blood mononuclear cells. Animals 2019, 9, 45 [CrossRef]

129. Ciliberti, M.G.; Francavilla, M.; Intini, S.; Albenzio, M.; Marino, R.; Santillo, A.; Caroprese, M. Phytosterols from Dunaliella tertiolecta reduce cell proliferation in sheep fed flaxseed during post partum. Mar. Drugs 2017, 15, 216. [CrossRef]

130. Christaki, E.; Bonos, E.; Florou-Paneri, P. Innovative Microalgae Pigments as Functional Ingredients in Nutrition. In Handbook of Marine Microalgae: Biotechnology Advances; Elsevier Inc.: Amsterdam, The Netherlands, 2015; pp. 223-243, ISBN 9780128011249.

131. Novoveská, L.; Ross, M.E.; Stanley, M.S.; Pradelles, R.; Wasiolek, V.; Sassi, J.F. Microalgal carotenoids: A review of production, current markets, regulations, and future direction. Mar. Drugs 2019, 17, 640. [CrossRef]

132. Sathasivam, R.; Ki, J.S. A review of the biological activities of microalgal carotenoids and their potential use in healthcare and cosmetic industries. Mar. Drugs 2018, 16, 26. [CrossRef]

133. Kishimoto, Y.; Yoshida, H.; Kondo, K. Potential anti-atherosclerotic properties of astaxanthin. Mar. Drugs 2016, 14, 35. [CrossRef] [PubMed]

134. Dolganyuk, V.; Belova, D.; Babich, O.; Prosekov, A.; Ivanova, S.; Katserov, D.; Patyukov, N.; Sukhikh, S. Microalgae: A promising source of valuable bioproducts. Biomolecules 2020, 10, 1153. [CrossRef]

135. Panche, A.N.; Diwan, A.D.; Chandra, S.R. Flavonoids: An overview. J. Nutr. Sci. 2016, 5. [CrossRef] [PubMed]

136. Goiris, K.; Muylaert, K.; Voorspoels, S.; Noten, B.; De Paepe, D.; E Baart, G.J.; De Cooman, L. Detection of flavonoids in microalgae from different evolutionary lineages. J. Phycol. 2014, 50, 483-492. [CrossRef]

137. Haoujar, I.; Cacciola, F.; Abrini, J.; Mangraviti, D.; Giu, D.; Oulad, Y.; Majdoub, E.; Kounnoun, A.; Miceli, N.; Taviano, M.F.; et al. The Contribution of Carotenoids, Phenolic Compounds, and Flavonoids to the Antioxidative Properties of Marine Microalgae Isolated from Mediterranean Morocco. Molecules 2019, 24, 4037. [CrossRef] [PubMed]

138. Koh, E.J.; Seo, Y.J.; Choi, J.; Lee, H.Y.; Kang, D.H.; Kim, K.J.; Lee, B.Y. Spirulina maxima extract prevents neurotoxicity via promoting activation of BDNF/CREB signaling pathways in neuronal cells and mice. Molecules 2017, 22, 1363. [CrossRef] [PubMed]

139. Carrero, A.; Vicente, G.; Rodríguez, R.; Linares, M.; Del Peso, G.L. Hierarchical zeolites as catalysts for biodiesel production from Nannochloropsis microalga oil. Catal. Today 2011, 167, 148-153. [CrossRef]

140. Velasquez-Orta, S.B.; Lee, J.G.M.; Harvey, A.P. Evaluation of FAME production from wet marine and freshwater microalgae by in situ transesterification. Biochem. Eng. J. 2013, 76, 83-89. [CrossRef]

141. Anto, S.; Mukherjee, S.S.; Muthappa, R.; Mathimani, T.; Deviram, G.; Kumar, S.S.; Verma, T.N.; Pugazhendhi, A. Algae as green energy reserve: Technological outlook on biofuel production. Chemosphere 2020, 242, 125079. [CrossRef] [PubMed]

142. Jacob-Lopes, E.; Maroneze, M.M.; Deprá, M.C.; Sartori, R.B.; Dias, R.R.; Zepka, L.Q. Bioactive food compounds from microalgae: An innovative framework on industrial biorefineries. Curr. Opin. Food Sci. 2019, 25, 1-7. [CrossRef]

143. Haimeur, A.; Mimouni, V.; Ulmann, L.; Martineau, A.S.; Messaouri, H.; Pineau-Vincent, F.; Tremblin, G.; Meskini, N. Fish Oil and Microalga Omega-3 as Dietary Supplements: A Comparative Study on Cardiovascular Risk Factors in High-Fat Fed Rats. Lipids 2016, 51, 1037-1049. [CrossRef] [PubMed]

144. Mayer, C.; Côme, M.; Ulmann, L.; Zittelli, G.C.; Faraloni, C.; Nazih, H.; Ouguerram, K.; Chénais, B.; Mimouni, V. Preventive effects of the marine microalga phaeodactylum tricornutum, used as a food supplement, on risk factors associated with metabolic syndrome in wistar rats. Nutrients 2019, 11, 1069. [CrossRef]

145. Peltomaa, E.; Johnson, M.D.; Taipale, S.J. Marine cryptophytes are great sources of EPA and DHA. Mar. Drugs 2018, 16, 3. [CrossRef]

146. Imbimbo, P.; D’Elia, L.; Liberti, D.; Olivieri, G.; Monti, D.M. Towards green extraction methods from microalgae learning from the classics. Appl. Microbiol. Biotechnol. 2020, 104, 9067-9077. [CrossRef] [PubMed]

147. Rumin, J.; Nicolau, E.; de Oliveira, R.G.; Fuentes-Grünewald, C.; Picot, L. Analysis of scientific research driving microalgae market opportunities in Europe. Mar. Drugs 2020, 18, 264. [CrossRef] 
148. Jones, A.D.; Boundy-Mills, K.L.; Barla, G.F.; Kumar, S.; Ubanwa, B.; Balan, V. Microbial lipid alternatives to plant lipids. In Microbial Lipid Production; Springer: Berlin, Germany, 2019; Volume 1995, pp. 1-32, ISBN 9781493994847.

149. Tang, D.Y.Y.; Khoo, K.S.; Chew, K.W.; Tao, Y.; Ho, S.H.; Show, P.L. Potential utilization of bioproducts from microalgae for the quality enhancement of natural products. Bioresour. Technol. 2020, 304, 122997. [CrossRef] 